\title{
Erratum to: Long-term efficacy of an attachment-based parental training program for single mothers and their children: a randomized controlled trial
}

\author{
Lonja Weihrauch • Ralf Schäfer • Matthias Franz
}

Published online: 21 May 2014

(C) Springer-Verlag Berlin Heidelberg 2014

Erratum to: J Public Health (2014) 22:139-153

DOI 10.1007/s10389-013-0605-4

In the first paragraph of the right column on page 150, it is mentioned that the effect sizes of the PALME program in relation to the general psychological symptom load (GSI) would be -0.52 immediate after intervention and -0.28 at follow-up measurement. These descriptions are wrong. The real effect sizes are -0.77 at post measurement ( $\mathrm{t} 2$ ) and -0.40 at follow-up-measurement (t3), as reported correctly in the result section on page 144 .

The online version of the original article can be found under doi:10.1007/ s10389-013-0605-4.

L. Weihrauch $\cdot$ R. Schäfer $\cdot$ M. Franz $(\bowtie)$

Medical Faculty, Clinical Institute of Psychosomatic Medicine and

Psychotherapy, University Düsseldorf, University Hospital (15.16),

Moorenstr. 5, 40225 Düsseldorf, Germany

e-mail: matthias.franz@med.uni-duesseldorf.de 